\title{
Improved storage and distribution of water in multi-storeyed residential buildings in semi-urban communities of India
}

\author{
V. Ravishankar \\ RV College of Engineering, \\ 8th Mile,Mysuru Road, \\ Bengaluru - 560059, India \\ Email: ravishankar_v@ymail.com
}

\begin{abstract}
The distribution of daily requirement of water in multi-storeyed semi-urban residential buildings in India involves pumping from the ground level to a reservoir at the top, and gravity feed to all levels below. String diagrams bring out the scope for reduction of unnecessary movement of water. A modified storage arrangement is proposed resulting in a small saving in energy required for water distribution, aggregating to a considerable amount for a locality over time, thus improving sustainability. The estimated savings reaches up to $25 \%-30 \%$ for buildings with four to six levels, increasing to $50 \%$ for high number of levels. Other benefits like metering, easy maintenance also could result. However, one of the problems involved in implementation is the higher initial costs involved in terms of foregone space occupied by the tanks at each level, and additional costs of storage tanks, which are key aspects in the economics of construction.
\end{abstract}

Keywords: multilevel storage; water distribution; pumping energy; high rise buildings; storage tanks; sustainability; construction economics; semi-urban; string diagram; energy savings; urban real estate; India.

Reference to this paper should be made as follows: Ravishankar, V. (2017) 'Improved storage and distribution of water in multi-storeyed residential buildings in semi-urban communities of India', Int. J. Sustainable Real Estate and Construction Economics, Vol. 1, No. 1, pp.67-76.

Biographical notes: V. Ravishankar has been with RV College of Engineering since 2009. Earlier, he was involved in turnkey projects in transportable communication terminals and quality assurance in engineering and service industries. He received his Master's degree in Industrial and Systems Engineering from Rutgers University, New Jersey.

\section{Introduction and scope}

One common characteristic of the urban zones worldwide is its tendency to keep on growing. With the urban population increasing at a faster pace than the increase in urban area required to accommodate the population, vertical expansion eventually results. Thus, multi-storeyed buildings and high rises are increasingly becoming common in many cities, especially in the developing economies like India (Seto et al., 2012). 
Energy saving and energy efficiency are high priorities for developing countries to reduce the environmental overshoot due to a high energy intensity. Households are important consumers of energy, using up more than $20 \%$ of the energy demand plus a considerable part of another $30 \%$ of energy through transportation of occupants to and from the dwelling units (Stoeglehner et al., 2014; Narodoslawsky and Stoeglehner, 2010). Any savings in energy in the operations of a household thus assumes importance to address the countries' interests in improving sustainability.

In India for example, the current population of over 30\% (Ellis and Roberts, 2016) in cities is likely to rise to $40 \%$ by 2030 . For major cities, population growth is faster on their peripheries beyond the administrative boundaries. Already there are five states with more of their population living in cities than in villages in India (Sankhe et al., 2010). Hence to address the need for housing, an increasing number of multi storeyed buildings would be required.

Water is one of the most essential commodities required. Water availability in an area depends on many factors such as climate changes, energy access, population and other factors including policies on water management (Pagan et al., 2016; Sahin et al., 2016). In India, the urban population depends largely on either the ground water accessed through open wells or deeper bore wells. Others depend on water supplied by the utility corporations. Whatever be the source, the water is pumped up to a reservoir on the top of the building from where it is gravity fed to the required outlets. Other ways of distribution in buildings are direct supply from the utility under pressure, which is available for a limited time in a day, and hydro-pneumatic pumping from the underground storage to all the levels in the building. Amongst these, the distribution with overhead storage is the most common method used for distribution in India (Indian Standard IS: 12183, 2004).

Water distribution in a residential building consumes energy for pumping water for storage. As the region develops economically, the demand of energy goes up. In India and other developing countries, the demand for energy is likely to outstrip supply (Seto et al., 2012; International Energy Agency, 2012). Also, currently the energy pricing includes a subsidy for a large section of the population, which will be reduced over a period of time as the country develops economically (International Energy Agency, 2015). The water availability in a region, though improved in the short term through foreign aid cannot be sustained in the long run in developing countries (Gopalana and Rajan, 2016). The distribution of water among different units in the building thus assumes importance for improved sustainability in the form of reduced energy consumption. Real estate developers involved in construction of high rise units would have an opportunity to address this issue as the water distribution costs are largely determined by the initial arrangement and placement of storage reservoirs for distribution.

In a developing country like India, both water and energy access is limited for a large population. Also, due to nexus between water and energy, savings in one leads to a better access to the other (International Energy Agency, 2015).

For the purposes of this study, water consumption is considered for an average family unit per day, living in a semi-urban locality in a developing country like India. While in a disaster scenario, water requirement is in the range of 20-30 litres per day per person (De Buck et al., 2015), during normal times an average urban resident in India requires about 150-200 litres per day per person (Indian Standard, BIS 1172: 1993). With some allowances for other needs of an urban population, a household unit of four persons can 
thus be assumed to consume on an average 1,000 litres of water per day. Solutions of automation systems in distribution of water as available in more developed areas as reported by $\mathrm{Li}$ (2013) are not considered since they are capital intensive and their operations cannot be sustained in the absence of maintenance supports in a typical semi-urban area.

Conventionally, water supply in mid-sized multi storeyed buildings is achieved by the use of lift pumps and a single roof mounted water tank, with gravity flow to the floors below [Indian Standard, IS: 12183 (Part 1) 2004]. An indicative estimate for pumping a day's requirement of 1,000 litres to an average $150 \mathrm{ft}$ head (3 storeys high, with head allowance for bends, friction, etc) can be worked out as below, using a pump with $60 \%$ efficiency:

$$
\text { Energy consumption, } \mathrm{E}=\frac{1,000 \times 150 \times 12 \times 25.4}{1,000} \times \frac{9.81}{0.6}=\begin{gathered}
900 \mathrm{~kJ} \text { per } \\
\text { household unit, }
\end{gathered}
$$

or, 0.25 billable electricity units per day.

To understand the movement of water to reach the roof tank and then the downward movement, an established industrial engineering technique called string diagram can be used. String diagrams are commonly used to analyse movement of entities in industrial operations (Kanawaty, 1993).

This paper concerns with improvement in water distribution in urban residential buildings in semi-urban communities of India, where multi storeyed residences with 4 or 5 levels is very common. Mid-size multi storeyed buildings with up to 5 levels only are considered, for simplicity. Since energy is only required to pump water up and the downward distribution is by gravity, water movement in the upward direction only is considered for analysis and comparison. Buildings with less than 6 storeys are considered (high rises are excluded since there are other considerations like multi stage pumping, booster pumps, and also additional municipal area regulations like separate storage for fire utilities, etc. But the principles outlined here apply equally to those high rises with single roof top water tank). Urban middle class house-holds are considered for comparison between existing and proposed ways of water distribution, since their average consumption pattern is more or less stable on a daily basis than other households. A simple rearrangement is proposed for improving the water distribution, which can be easily planned for implementation in new constructions.

\section{The string diagram}

There are many industrial engineering techniques to identify and reduce inefficiencies in operations of an organisation, like flow process charts, work and method study, etc. Of these, the string diagram is one which is used to identify unnecessary movements contributing to inefficiencies. Here a string is used to trace and measure the path of workers, material or equipment on a scale model. The string or thread is then used to measure the total distance travelled (Kanawaty, 1993). When the total movement is made very clear, it becomes easy to re-sequence the operations or reposition stations so as to minimise movement and speed up the process. Unnecessary movement is also one of the identified wastes in lean practice implementations worldwide. 
In Figure 1, a worker builds boxes by going to each station around the machine shop. With a string diagram, the distance travelled to build one box is measured, using a pin board and scale map of the workshop area. The diagram clearly shows the unnecessary zigzag movement. Because the operation is sequential, the machines are simply moved into a U-shape, resulting in reduced movement, and thus an easier and faster process, and also usage of less floor space (Straker, 1995). The total length of movement is then compared to know the potential savings due to improved operations by way of reduced movement.

Figure 1 String diagram example

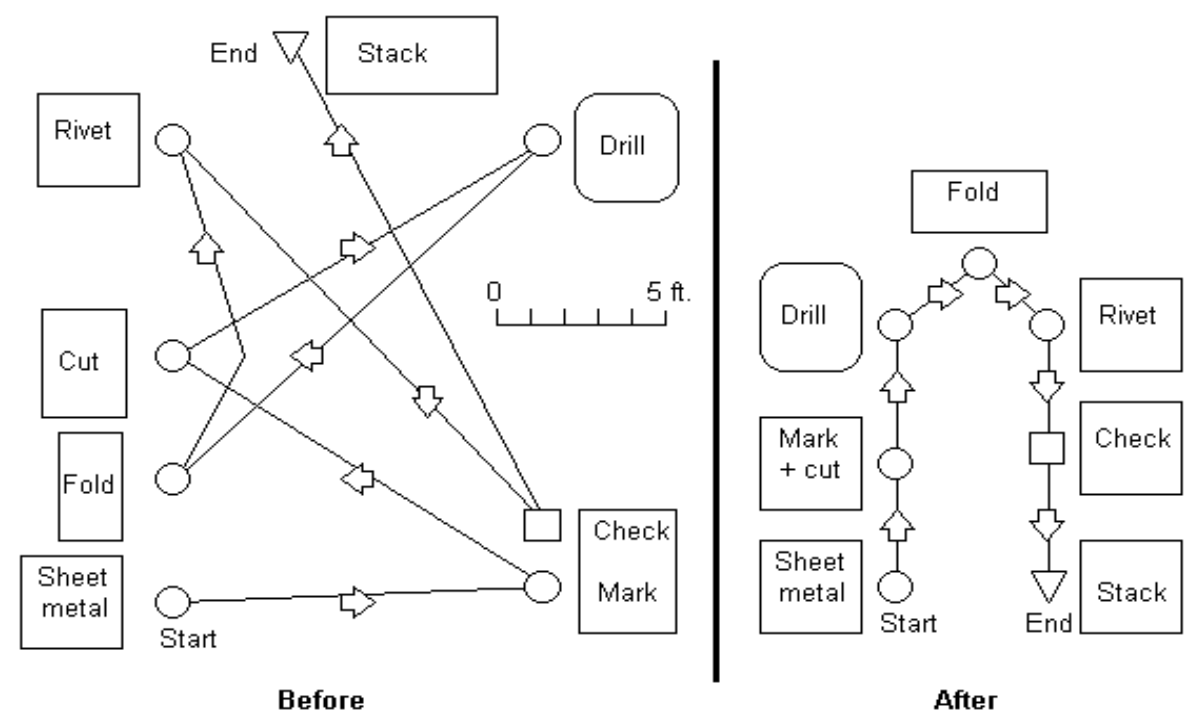

Source: Reprinted from Straker (1995)

The idea of identifying unnecessary movement can be extended to the distribution of water in multi storeyed buildings. By keeping a day's consumption as a unit, the string diagram can be drawn for the upward movement of water as it gets pumped up using external energy.

\section{Current practice of water distribution}

Currently, the apartments satisfy the needs of the residents with one water source at the top [Indian Standard, IS: 12183 (Part 1) 2004]. By depicting the upward movement of the daily requirement of water by lines, the current practice string diagram can be drawn as in Figure 2(a). Each solid line represents one full day's consumption of water. Assumptions to ease the representation are made as follows: 
1 Each level is $\mathrm{h}$ metres high and the water is pumped from the basement at level $\mathrm{h}$ metres below ground level to a level at $\mathrm{h}$ metres above the top-most level.

2 The average water consumption per unit per day, $\mathrm{q}$ litres is constant across different levels. Then $(n q)$ litres of water need to be pumped to a height of $(n h+2 h)$ metres every day in the building.

The total work done to pump the required amount of water is

$$
W=9.81 \times n q \times(n h+2 h) \text { joules }=9.81 \times q h n \times(n+2) \text { joules },
$$

assuming the density of water to be $1,000 \mathrm{~kg} / \mathrm{m}^{3}$, and ignoring the horizontal movements and flow through bends and valves (all factors other than height movement being common to the method to be proposed, these factors are not considered for comparison).

Figure 2 (a) Current water supply string diagram for flow of water up (b) Storage at two levels in a residential building in Bengaluru (see online version for colours)

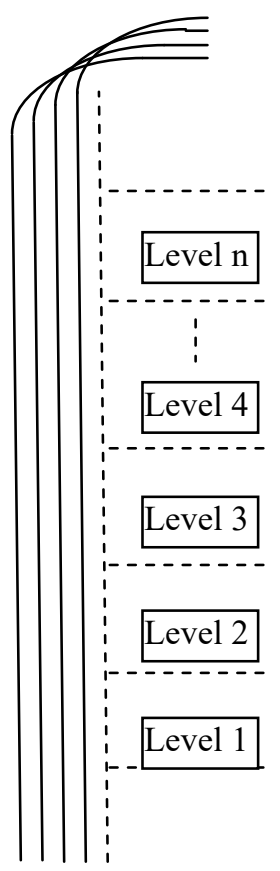

(a)

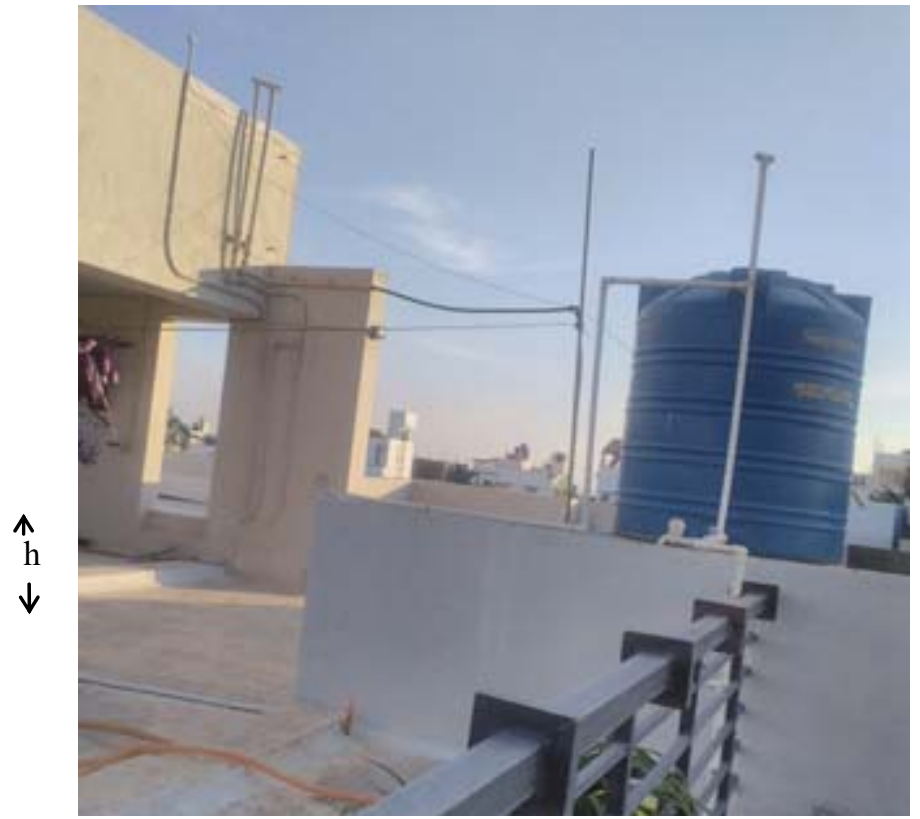

(b)

From this arrangement, the following observations can be made:

1 water travels to the top for all levels and comes back down all the way to each level

2 there is a high pressure at the outlets for units at the bottom and moderate pressure for units at the upper levels. 


\section{Proposed way of pumping water up}

Instead of water travelling all the way up and then all the way down, each level gets water supplied from a separate storage tank just one level above. This arrangement is already followed in a limited way in many separate households, as observed in a typical locality in Bengaluru, in south India (not apartments) as shown in Figure 2(b).

The water flow in the upward direction is shown in Figure 3, in which the water for level 1 is pumped to a height of $2 \mathrm{~h}$ metres above ground level, water for level 2 is pumped to a height of $3 \mathrm{~h}$ metres above ground level, and so on.

Figure 3 Proposed arrangement string diagram for flow of water up

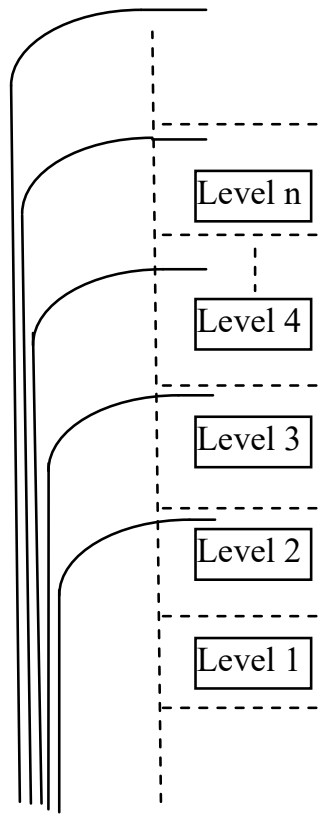

The total work done in order to pump water to all the levels in this arrangement is

$$
\begin{aligned}
W^{\prime} & =9.81 \times 3 h q+9.81 \times 4 h q+\ldots+9.81 \times(n+2) h q \text { joules } \\
& =9.81 \times(3+4+\ldots+n+2) h q=9.81[n(n+5) / 2] h q \text { joules }
\end{aligned}
$$

It can be observed that there is a separate water source for each unit of the building. Comparing with the current arrangement shown in Figure 2, it is readily seen that in the proposed arrangement, the density of lines indicating water flow is less, leading to the conclusion that there are savings. Direct comparison of the pumping energy computed, $\mathrm{W}$ and $W^{\prime}$ is shown in Table 1 for different no. of levels in a building, and in Table 2 for different amounts of consumption. It is clearly seen that the \% savings varies with the no. of levels. The more the no. of levels, the more the savings realised. Figure 4 shows the $\%$ savings plotted against the no. of levels. The savings seem to get stabilised at around $40 \%$. The important point to note is that for no. of levels as less as even 3 or 4 , there is a considerable savings of $20 \%-25 \%$. 
Improved storage and distribution of water

Table 1 Potential savings in water pumping for different number of levels (for a constant consumption q)

\begin{tabular}{lcccc}
\hline $\begin{array}{l}\text { No. of } \\
\text { levels, } \\
n\end{array}$ & $\begin{array}{c}W=9.81 q \mathrm{qhn}(n+2), \\
\text { Joules }\end{array}$ & $W^{\prime}=\begin{array}{c}9.81 \mathrm{qh}[\mathrm{n}(\mathrm{n}+5) / 2], \\
\text { Joules }\end{array}$ & $\begin{array}{c}\text { Savings } W-W^{\prime}= \\
\text { 4.905qhn }(n-1) \text { Joules }\end{array}$ & $\begin{array}{c}\% \text { savings, } \\
(n-1) / 2(n+2)\end{array}$ \\
\hline 1 & $29.43 \mathrm{qh}$ & $29.43 \mathrm{qh}$ & 0 & $0 \%$ \\
2 & $78.48 \mathrm{qh}$ & $68.67 \mathrm{qh}$ & $9.81 \mathrm{qh}$ & $12.5 \%$ \\
3 & $147.15 \mathrm{qh}$ & $117.72 \mathrm{qh}$ & $29.43 \mathrm{qh}$ & $20 \%$ \\
4 & $235.44 \mathrm{qh}$ & $176.58 \mathrm{qh}$ & $58.86 \mathrm{qh}$ & $25 \%$ \\
5 & $343.35 \mathrm{qh}$ & $245.25 \mathrm{qh}$ & $98.1 \mathrm{qh}$ & $28.5 \%$ \\
6 & $470.08 \mathrm{qh}$ & $323.73 \mathrm{qh}$ & $147.15 \mathrm{qh}$ & $31.3 \%$ \\
\hline
\end{tabular}

Figure $4 \%$ savings for a constant quantity of consumption per unit of dwelling (see online version for colours)

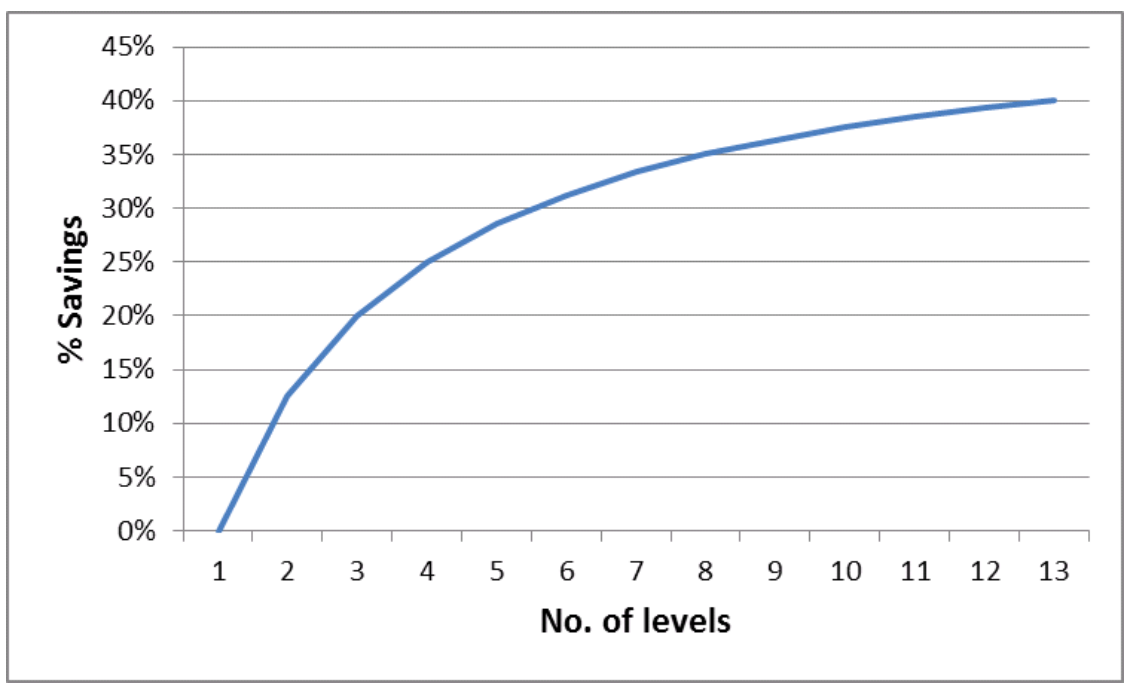

Table 2 Potential savings in water pumping for different quantity of consumption (for $n$ levels)

\begin{tabular}{lcccc}
\hline $\begin{array}{l}\text { Consumption, } \\
\text { q litres }\end{array}$ & $\begin{array}{c}W=9.81 q h n(n+2), \\
\text { Joules }\end{array}$ & $\begin{array}{c}W^{\prime}=9.81 q h[n(n+5) / 2], \\
\text { Joules }\end{array}$ & $\begin{array}{c}\text { Savings } W-W^{\prime}= \\
\text { 4.905qhn }(n-1) \text { Joules }\end{array}$ & $\begin{array}{c}\% \text { savings, } \\
(n-1) / 2(n+2)\end{array}$ \\
\hline 1,000 & $9810 \mathrm{hn}(\mathrm{n}+2)$, & $9810 \mathrm{~h}[\mathrm{n}(\mathrm{n}+5) / 2]$ & $4905 \mathrm{hn}(\mathrm{n}-1)$ & $(\mathrm{n}-1) / 2(\mathrm{n}+2)$ \\
1,500 & $14720 \mathrm{~h} \mathrm{n}(\mathrm{n}+2)$ & $14720 \mathrm{~h}[\mathrm{n}(\mathrm{n}+5) / 2]$ & $7360 \mathrm{hn}(\mathrm{n}-1)$ & $(\mathrm{n}-1) / 2(\mathrm{n}+2)$ \\
2,000 & $19620 \mathrm{hn}(\mathrm{n}+2)$ & $19620 \mathrm{~h}[\mathrm{n}(\mathrm{n}+5) / 2]$ & $9810 \mathrm{hn}(\mathrm{n}-1)$ & $(\mathrm{n}-1) / 2(\mathrm{n}+2)$ \\
2,500 & $24530 \mathrm{hn}(\mathrm{n}+2)$ & $24530 \mathrm{~h}[\mathrm{n}(\mathrm{n}+5) / 2]$ & $12265 \mathrm{hn}(\mathrm{n}-1)$ & $(\mathrm{n}-1) / 2(\mathrm{n}+2)$ \\
3,000 & $29430 \mathrm{hn}(\mathrm{n}+2)$ & $29430 \mathrm{~h}[\mathrm{n}(\mathrm{n}+5) / 2]$ & $14715 \mathrm{hn}(\mathrm{n}-1)$ & $(\mathrm{n}-1) / 2(\mathrm{n}+2)$ \\
\hline
\end{tabular}


Apart from energy saving there are other benefits in the proposed arrangement:

1 A uniform outlet pressure is possible since each unit gets water from the same height differential. In the existing arrangement, sometimes pressure reducers are necessary to control the outlet pressure, else the excess pressure may lead to water hammering phenomenon and damage to pipe fittings.

2 Instead of a large weight bearing tank housed at the top, the distributed arrangement distributes the load too, improving the structural integrity of the building.

3 Due to separation of storage at each level, there is a possibility of easy maintenance at the supply side without the supply for other units being disturbed.

4 Individual metering and hence a better control on water distribution is possible in the supply side. Also, the possibility of limiting the usage for high volume users exists from the supply side, which is not possible with a single overhead water tank.

5 Even in high rises like in buildings with more than 6 floors, the booster pumps installed can be of reduced capacities with storage points at each level.

6 The delivery side plumbing from individual tank to individual unit will relatively be simpler and less expensive than in the existing arrangement.

\section{Implementation issues}

In spite of a host of advantages, some issues remain for implementing the proposed arrangement. These are:

1 Extra space is required for housing a storage tank at each level. Space being at a premium in areas becoming urbanised, this is an important draw-back for residents who will prefer utilising the space for other uses. However, this cost can be made up by the reduction realised on a daily basis for water distribution.

2 High costs result, also due to individual storage facilities, valves and associated supply side plumbing.

3 Faster delivery to storage tanks at upper levels might require additional control.

The operational and maintenance cost of the plumbing involved in the new arrangement would be almost the same, since the higher costs involved in the maintenance of supply side plumbing is balanced by savings resulting from lower maintenance costs in the delivery side plumbing as compared to the existing arrangement. According to the observations made in 12 semi-urban areas surrounding Bengaluru, this model is not prevalent in $95 \%$ of the buildings. The few households having a multi level storage of water all have only 2 levels in the building. A simple survey points to the desire to keep initial costs low rather than look at the long term operating costs. However, keeping in view of the savings on a daily basis, and the rising cost of energy, the additional initial cost can be recovered in a matter of time. 


\section{Conclusions}

With the help of string diagram, it is brought out that the current way of water supply consumes more energy compared to the proposed way of water distribution. Preliminary computations with just two to five floors show that the energy savings realised are $12.5 \%$ to $28.5 \%$ in pumping water up for storage. The savings will be higher with more number of floors and more quantity of usage. The proposed method has a host of other advantages apart from reduced energy requirements, like uniform outlet pressure, easy maintenance and possibility of better supply side control. However, the proposal faces difficulties in implementation due to requirement of extra space for housing a tank at each level and additional initial costs for plumbing. Further work which can be carried out in this direction are: modelling the flow with probabilistic consumption, inclusion of factors to take care of bends, restrictions, friction in pipes, modelling flows in high rises, and pay-back period computations to demonstrate economic viability.

\section{References}

De Buck, E., Borra, V., De Weerdt, E., Veegaete, A.V. and Vandekerckhove, P. (2015) 'A systematic review of the amount of water per person per day needed to prevent morbidity and mortality in (post-) disaster settings', PLoS One, May [online] http://journals.plos.org/ plosone/article?id=10.1371/journal.pone.0126395 (accessed 14 September 2016).

Ellis, P. and Roberts, M. (2016) Leveraging Urbanisation in South Asia: Managing Spatial Transformation for Prosperity and Livability [online] https://openknowledge.worldbank.org/ handle/10986/22549 (accessed 14 July 2016).

Gopalana, S. and Rajan, R.S. (2016) 'Has foreign aid been effective in the water supply and sanitation sector? Evidence from panel data', World Development, September 2016, Vol. 85, pp.84-104.

Indian Standard BIS 1172: 1993, Reaffirmed 2013, Code of Basic Requirements for Water Supply, Drainage and Sanitation, Bureau of Indian Standards, New Delhi.

Indian Standard IS: 12183 (Part 1) (2004) Code of Practice for Plumbing in Multi-Storeyed Buildings, Bureau of Indian Standards, New Delhi.

International Energy Agency, Paris (2012) Understanding Energy Challenges in India [online] http://www.iea.org/publications/freepublications/publication/partner-country-series--understanding-energy-challenges-in-india.html (accessed 8 December 2016).

International Energy Agency, Paris (2015) India Energy Outlook - World Energy Outlook Special Report 2015 [online] http://www.worldenergyoutlook.org/media/weowebsite/2015/IndiaEnergyOutlook_WEO2015 .pdf (accessed 8 December 2016).

Kanawaty, G. (1993) Introduction to Work Study, International Labour Office, Geneva.

Li, R.Y.M. (2013) 'The usage of automation system in smart home to provide a sustainable indoor environment: a content analysis in Web 1.0', International Journal of Smart Home, Vol. 7, No. 4, pp.47-60.

Narodoslawsky, M. and Stoeglehner, G. (2010) 'Planning for local and regional energy strategies with the ecological footprint', Journal of Environmental Policy \& Planning, Vol. 12, No. 4, pp.363-379.

Pagan, B.R., Ashfaq, M., Rastogi, D., Kendall, D.R., Kao, S-C., Naz, B.S., Mei, R. and Pal, J.S. (2016) 'Extreme hydrological changes in the southwestern US drive reductions in water supply to Southern California by mid century', Environmental Research Letters, Vol. 11, No. 9, doi: 10.1088/1748-9326/11/9/094026. 
Sahin, O., Siems, R.S., Stewart, R.A. and Porter, M.G. (2016) 'Paradigm shift to enhanced water supply planning through augmented grids, scarcity pricing and adaptive factory water: a system dynamics approach', Environmental Modelling \& Software, January 2016, Vol. 75, pp.348-361.

Sankhe, S., Vittal, I., Dobbs, R., Mohan, A., Gulati, A., Ablett, J., Gupta, S., Kim, A., Paul, S., Sanghvi, A. and Sethy, G. (2010) India's Urban Awakening: Building Inclusive Cities, Sustaining Economic Growth, McKinsey Global Institute [online] http://www.mckinsey.com/global-themes/urbanization/urban-awakening-in-india (accessed 20 November 2015)

Seto, K.C., Güneralp, B. and Hutyra, L.R. (2012) 'Global forecasts of urban expansion to 2030 and direct impacts on biodiversity and carbon pools', Proceedings of the National Academy of Sciences in the United States of America, August.

Stoeglehner, G., Baaske, W., Mitter, H., Niemetz, N., Kettl, K-H., Weiss, M., Lancaster, B. and Neugebauer, G. (2014) 'Sustainability appraisal of residential energy demand and supply - a life cycle approach including heating, electricity, embodied energy and mobility', Energy, Sustainability and Society, December, Vol. 4, No. 1, Article 24.

Straker, D. (1995) A Toolbook for Quality Improvement and Problem Solving, Prentice Hall, London. 